\title{
Sizing of Small Grid-off Renewable Sources Hybrid in Conditions of North-Eastern Slovakia
}

\author{
Miroslav Mikita ${ }^{1 *}$, Michal Kolcun ${ }^{2}$, Zsolt Čonka ${ }^{3}$, Martin Vojtek ${ }^{4}$, Michal Špes \\ ${ }^{1-5}$ Technical University of Košice
}

\begin{abstract}
This article deals with sizing of hybrid renewable sources applications that are suitable in remote areas where grid connection is unavailable or connection to grid is expensive. Depending on the size of installed capacity of each photovoltaic, wind power and small water power plant, such a system can be used to power small systems with hundreds watts consumption and also can be used to supply entire villages where the connected load has a power in the order of up to megawatts. All depends on the installed performance of different sources, types and sizes of the storage device and the equipment, to be an island power system. Such hybrid renewable sources systems are strongly dependent on the weather conditions of the site of their construction. The present paper is about a small grid-off system that powers a small single house. This house is modelled as family house with a two-membered family. The system consists of a photovoltaic cell field, a wind turbine, a small hydroelectric power plant, and a battery bank as a cumulating source. This system is designed to power a whole daily consumption load without electricity outages.
\end{abstract}

Keywords - Grid-off systems, hybrid renewable source, photovoltaic, small hydroelectric power plant, wind turbine.

\section{INTRODUCTION}

Hybrid renewable sources systems have been proposed by many researchers as a sufficient source of electricity distant sites for which it is difficult to connect at electrical grid. The demand for energy of hybrid renewable sources in distant sites is covered by using the potential of renewable sources available at the site of the system. This system using various types of renewable energy sources like sun-powered solar photovoltaic plants, turbines using wind energy, micro-hydroelectric power sources (MHP) etc. can be chosen for generating power directly at the site. Hybrid renewable sources systems have the potential to combine advantages such as energy capability and energy management, and the results from the chosen mix of renewable energy sources. The use of different renewable sources of energy minimizes the requirements for storage of electricity and raises the predictability of electric power delivery and quality of electricity, which is also an important factor nowadays. For grid off using, these structures are usually combined with repository devices to obtain the continuous supply from renewable energy sources like solar and wind. Controlling systems are the most important parts of hybrid renewable sources systems that maintain the information and communication between many devices from which the system consists. Control system manages the output of renewable energy sources and also produces the signs for planning of storing parts of the system and using surpluses in energy generation. Such system helps to secure the storage system from overcharging and to operate the storage system in rated limits [1]-[2].

Not all distant areas have available adequate renewable energy sources, and, in this case, it is needed to add some conventional choice as a diesel/petrol/gasoline fuel generator with renewable energy sources to cover the whole electrical supply [3].

\section{A. Hybrid Energy System Types}

Hybrid renewable energy system may be combined as is shown in Fig. 1. This type of renewable energy systems is called "hybrid" because it consists of at least two renewable energy sources in order to fully supply a complete electrical load. Energy sources may be renewable or conventional combined, or energy storage devices. Hybrid renewable energy systems may work connected to the grid (grid-on) where the main priority of the system is to cover the sites' full electrical load and if surplus is generated supplying the grid, or as grid-off systems that produce energy separately from the grid in remote sites [4]-[5].

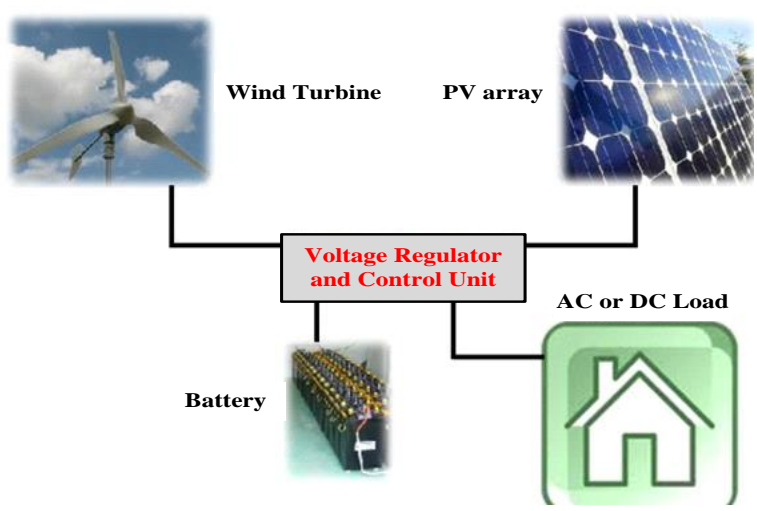

Fig. 1. Scheme of a hybrid system. 


\section{HOMER}

HOMER (Hybrid Optimization Model for Electric Renewables) is a simulation software invented by the U.S. National Renewable Energy Laboratory (NREL) to help in the developing and designing of renewable energy hybrid systems. HOMER simulates the behavior of energy-power delivering systems and their cost during the lifecycle, which is the amount of money spent for a system and the costs of services over its life cycle; each of these possibilities are modeled by HOMER. Choices as units for distributing generation (DG) units, standalone systems, off-grid systems and grid-on systems for delivery in remote areas, and other choices, can be calculated by HOMER. Simulation, optimization, and sensitivity analysis are the three principal tasks performed in HOMER [6].

\section{A. Simulation in HOMER}

In simulation, HOMER describes technical specifications and cost during the life cycle of a hybrid renewable sources system for hourly data per year. The next step is calculation of the hybrid renewable system configuration and the strategy for operation for the power delivery parts, which are tested to inspect how these parts work in setting during a calculated year. The simulation possibilities of HOMER is a long-time simulation of a hybrid renewable sources system [7].

\section{B. Sizing Optimization in HOMER}

HOMER optimizes and shows the appropriate systems and their compositions with deciding the search space entered by the developer, sorted by the cheapest choice of the hybrid renewable sources system, depending on the total net present cost. The results of simulation shows the best configuration of a hybrid renewable sources system, the optimization calculate and the optimal hybrid renewable sources system. HOMER describes the best solution for the configuration of a hybrid renewable sources system, which is the system with the minimum net present cost totally and keeping the developer's efforts [6].

\section{Sensitivity Analysis}

Sensitivity analysis can analyze the reactions of the parts of system changes in time. HOMER searches for optimal rates for the sizes and quantities of the equipment that is calculated in the hybrid renewable sources system and the evaluated constraints [8].

\section{MODELING OF HYBRID RENEWABLE SOURCES SYSTEM}

A hybrid renewable energy sources grid-off system is usually composed of a renewable source as wind and photovoltaic connected with a battery and other repository devices.

Fig. 2. illustrates a small-scale hybrid configuration that will be used as the basis of the case study simulations.

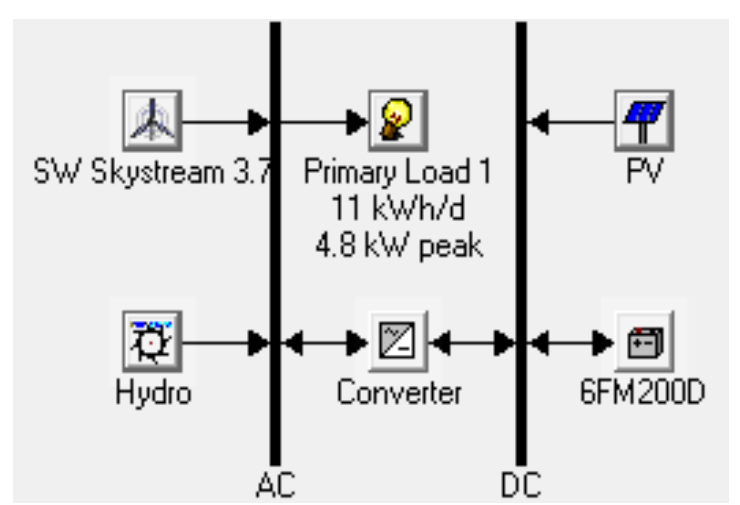

Fig. 2. Implementation of the hybrid system.

\section{A. Electrical Load}

An ordinary house in Slovakia with two inhabitants probably spends around $11 \mathrm{kWh} / \mathrm{d}$ with a top requirement approximately $2,4 \mathrm{~kW}$. The data of daily consumption for an off-grid house in the location of Čirč was designed. This remote house has various electrical equipment as random house in this area, such as refrigerator, pc assembly, TV, washing machine, electric kettle, lights, oven, iron, electric cooker, radio, freezer, and so on.

Typical daily energy consumption is higher in the evening hours, as it can be seen in Fig. 3 .

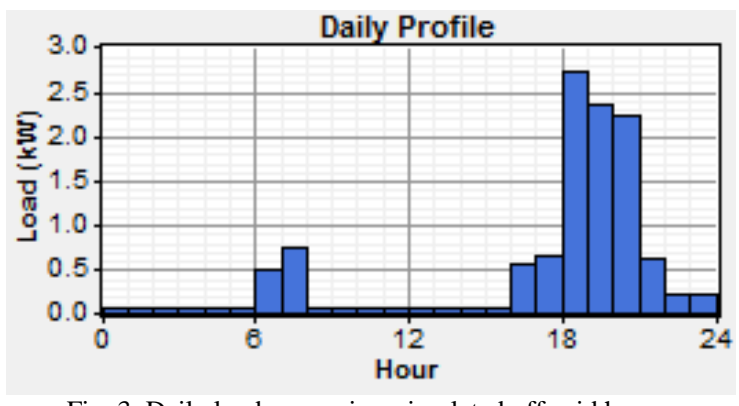

Fig. 3. Daily load course in a simulated off-grid house.

\section{B. Solar Irradiance Data}

The irradiance data of Čirč were gathered by HOMER from NASA. For geographical position data in HOMER, $49^{\circ} 16^{\prime} \mathrm{N}$ latitude and $20^{\circ} 55^{\prime}$ E longitude were used to obtain the data for computing the solar system. Those are the geographical position data of the centre of Čirč. HOMER generates the solar radiance data for a whole year by using the Graham scan algorithm. Graham scan algorithm gives sensible hourly values, which is simply to treat requiring only the geographical latitude and monthly average values of solar irradiance. The fabricated values show the real daily and hourly data for a whole year. The fabricated values are generated with sure numerical features that flash universal averages. So, the values fabricated for a precise area will not completely depict the attributes of the original solar sources. But testing results depicted that fabricated solar values produced basically equal simulation results as the measured actual values. Solar monthly average values for the simulated site are shown in Fig. 4. 


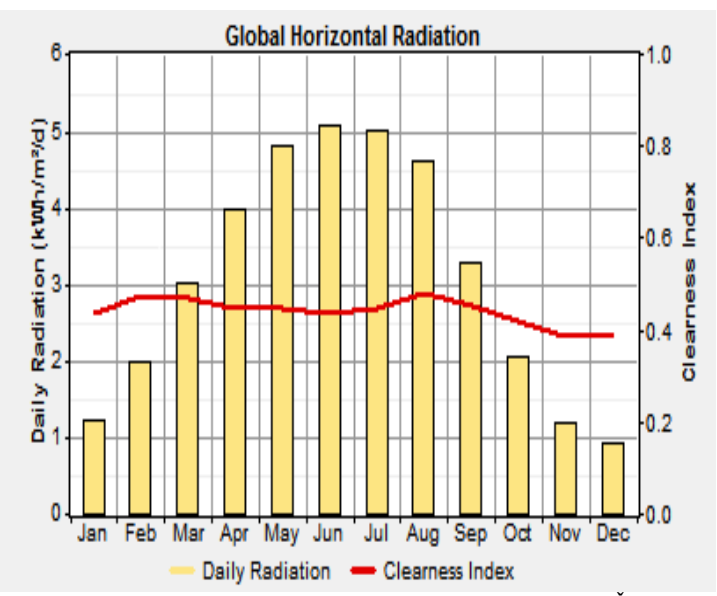

Fig. 4. Solar radiation and clearness index data for Čirč.

\section{Wind Speed Data}

The monthly regular wind speed value from the moderate of ten years was obtained from the NASA resources webpage established on the geographical coordinates of the site. The yearly moderate wind speed value for the site is $3.5 \mathrm{~m} / \mathrm{s}$ measured with the anemometer peak $20 \mathrm{~m}$. The wind speed possibility and moderate monthly speed through annual period are also checked (see Fig. 5).

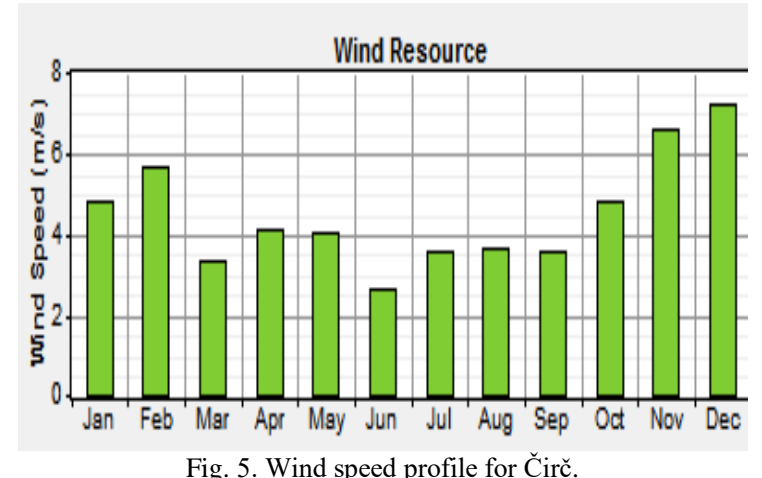

\section{Water Resource Data}

The monthly average water flow data can be seen in Fig. 6 .

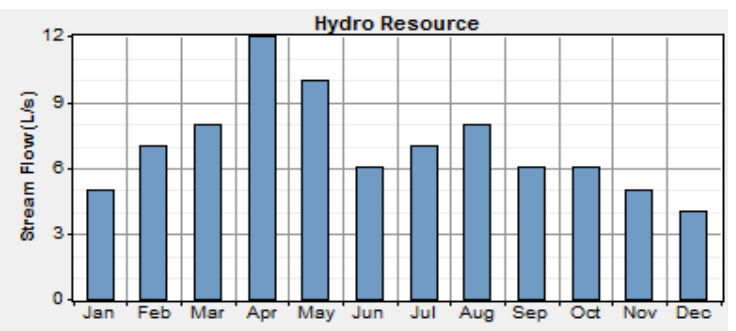

Fig. 6. Water flow profile.

\section{E. PV System}

A solar cell is an electrical device constructed to convert the solar radiation directly into electricity. Solar cells are constructed to modules to gain the required voltage and current. A PV array is a combination of PV modules connected to a larger power generation system. A PV array generates a DC voltage and current that are needed to empower the designed off-grid house.

HOMER recognizes the PV array as installed kilowatts, not as square meters. So, there is not the necessity to calculate the efficiency.

\section{F. Wind System}

In the simulations, the wind turbine SW SKYSTREAM 3.7, the most recent generation of small turbines, was used. It can be used as a residential power source and is a good choice to empower hybrid renewable sources for off-grid homes.

SW SKYSTREAM 3.7 was designed for very low winds starting at $3.5 \mathrm{~m} / \mathrm{s}$ and producing full output at $10.3 \mathrm{~m} / \mathrm{s}$.

\section{G. Converter}

The converter is an electrical device that converts direct current into alternate current. Converters are the most important part in the hybrid systems. There are many various types of converters. The power optimizer converts the power from solar panels using the maximum power point tracker. Micro-inverters are directly connected to solar module. String inverters and central inverters are used in larger systems.

\section{H. Batteries}

The battery is modelled as a kinetic mode in the HOMER software, the batteries' model consisting of two tanks. First tank is the charger of available capacity, and second tank represents the discharge of power considering limits. Batteries Vision 6FM200D are selected for the simulation because they are widely used and are economicaly beneficial. It is decided to take up from 2 to 30 batteries for the HOMER search space. From the catalogue, the type 6FM200D has the nominal voltage of $12 \mathrm{~V}$ and the nominal capacity of $200 \mathrm{Ah}$.

\section{SIMULATION RESULTS}

When the system iss modelled and each componet is set in the simulation area of hybrid system, the program can be ran. HOMER optimization software was used to simulate the hybrid renewable sources system. Sofware calculates many options which were set to search the space and choose the best option of sizing of all components. A large number of varieties are considered and calculated for choosing the best hybrid renewable system which optimally covers the load of a hybrid system. This system is optimised by HOMER's algorithms, and the best possibility is evaluated as a choice for the best configuration of a hybrid renewable system.

Fig. 7 shows optimal sizing of hybrid systems that are based at simulation. These systems can provide full electricity for the model off-grid house load consumption, and they consist of a PV cells field the size of $3 \mathrm{~kW}$, the wind turbine $\mathrm{SW}$ 
SKYSTREAM 3.7, hydro turbine the size of $0.14 \mathrm{~kW}$, eight batteries Vision 6FM200D, and a converter the size of $3 \mathrm{~kW}$.

Figures 8 and 9 show daily balance chacteristics in typical winter and summer days. The characteristics of battery state of charge, the production of energy from PV field, wind turbines small and hydroelecric power plant, the load curve are showed.

\begin{tabular}{|c|c|c|c|c|c|c|c|c|}
\hline 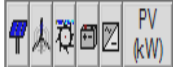 & \$3.7 & $\begin{array}{l}\text { Hydro } \\
\text { (kW) }\end{array}$ & 6FM200D & $\begin{array}{l}\text { Conv. } \\
\text { (KW) }\end{array}$ & $\begin{array}{l}\text { Intitial } \\
\text { Capital }\end{array}$ & $\begin{array}{l}\text { Operding } \\
\operatorname{Cost}(s / y r)\end{array}$ & $\begin{array}{l}\text { Total } \\
\text { NPC }\end{array}$ & \begin{tabular}{|c|c|} 
COE & $R$ \\
$(\$ / k W h)$ & $F i$
\end{tabular} \\
\hline 人等因图 & 1 & 0.140 & 8 & 3.0 & $\$ 12,970$ & 156 & $\$ 14,964$ & 0.301 \\
\hline
\end{tabular}

Fig. 7. Sizing of the calculated hybrid system.

As it can be seen, the system covers the whole consumption of the model house: when production is lower than consumption, the battery bank works as a reserve source of electricity; and when production is higher, the battery bank acummulates the surplus of electricity.

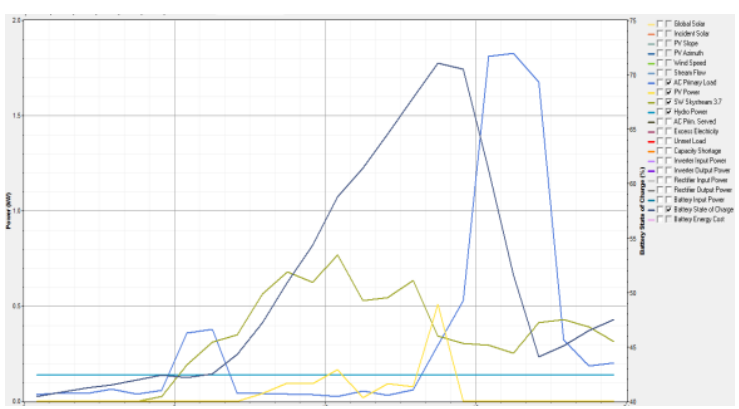

Fig. 8. Characteristics of energy balance in winter days.

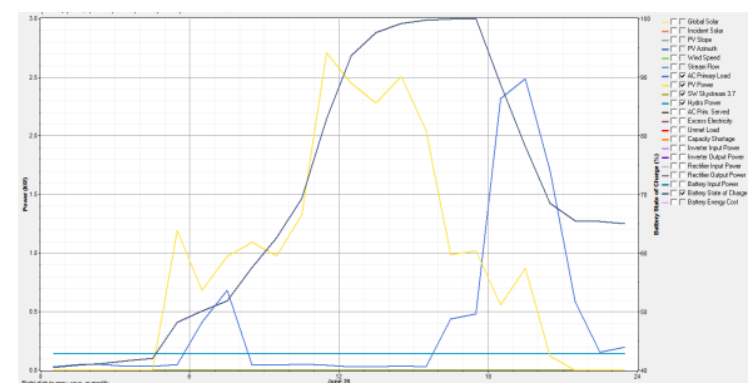

Fig. 9. Characteristics of energy balance in summer days.

\section{CONCLUSION}

The proposed modelled hybrid system fully covers the daily consumption of a modeled house. The system consists of a $3 \mathrm{~kW}$-sized PV field, the wind turbine SW SKYSTREAM 3.7, a small hydroelectric power plant, a battery bank consisting of eight batteries Vision 6FM200D, and a converter the size of $3 \mathrm{~kW}$.

Hybrid systems are suitable to cover electricity consumption of the houses in areas with good weather conditions. Choosing optimal sizes of the elements of hybrid systems is important from the economic point of view, because these systems are expensive and the right sizing of the elements of a hybrid system can reduce the amount of money needed for purchasing such a system.

Hybrid systems are a solution to bring electricity to remote areas where construction of a grid is expensive or unlikely. Recently, purchasing prices of such systems are decreasing and these systems are becoming available.

\section{REFERENCES}

[1] P. Nema, R. K. Nema and S. Rangnekar, "A current and future state of art development of hybrid energy system using wind and PV-solar, a review," Renewable and Sustainable Energy Rev, vol. 13, issue 8, pp. 2096-3103, 2009. http://dx.doi.org/10.1016/j.rser.2008.10.006

[2] J. L. Bernal-Agustín and R. Dufo-López, "Simulation and optimization of stand-alone hybrid renewable energy systems," Renewable and Sustainable Energy Rev., vol. 13, issue 8, pp. 2111-2118, 2009. ttp://dx.doi.org/10.1016/j.rser.2009.01.010

[3] W. Zhou, et al., "Current status of research on optimum sizing of standalone hybrid solar-wind power generation systems," Applied Energy, vol. 87, issue 2, pp. 380-389, 2010. http://dx.doi.org/10.1016/j.apenergy.2009.08.012

[4] R. Luna-Rubio, et al., "Optimal sizing of renewable hybrids energy systems: A review of methodologies," Solar Energy, vol. 86, issue 4, pp. 1077-1088, 2012. http://dx.doi.org/10.1016/j.solener.2011.10.016

[5] S. Ashok, "Optimised model for community-based hybrid energy system" Renewable Energy, vol. 32, issue 7, pp. 1155-1164, 2007. http://dx.doi.org/10.1016/j.renene.2006.04.008

[6] T. Lambert, P. Gilman and P. Lilienthal, "Micropower system modeling with HOMER," in Integration of Alternative Sources of Energy, 2006, ch. 15, pp. 379-385. http://dx.doi.org/10.1002/0471755621.ch15

[7] O. Hafez and K Bhattacharya, "Optimal planning and design of a renewable energy based supply system for microgrids" Renewable Energy, vol. 45, pp. 7-15, 2012. http://dx.doi.org/10.1016/j.renene.2012.01.087

[8] J. Fulzele and S. Dutt, "Optimium planning of hybrid renewable energy system using HOMER” Int. J. of Elect. and Computer Eng., vol. 2, no. 1, pp. 68-74, 2011. http://dx.doi.org/10.11591/ijece.v2i1.157 